cytoplasm, serous-like cells, squamous cells, and similarly considered to derive from an endometrioid linage, leading to deletion of the seromucinous carcinoma ${ }^{11}$ (but not borderline) chapter from the latest WHO classification. Of note, the possible association of ovarian MLAs with microsatellites or HRD gene status is largely unknown; we found no relevant abnormality in the current case.

Finally, given the rarity of these tumours, reports have been limited to only a few cases without considerable follow up, so their clinical course was virtually unknown until recently. However, a recent multicentre, retrospective study gathering 25 ovarian cases (four of which were previously published), ${ }^{4,6}$ among cases from other localisations, revealed a mean age at diagnosis of 61 years (range 36-81), FIGO stage II-IV in almost $40 \%$ of cases and recurrences in $42 \%$ of them, usually distant, often pulmonary, with a 5-year progression-free and overall survival of $68 \%$ and $71 \%$, respectively, implying that these are aggressive tumours. ${ }^{1}$

To conclude, ovarian MLAs should be suspected when an endometrioid morphology is encountered, but with more variable architectures and absence of hormone receptors. GATA3 and TTF1 positivity will then help in the diagnosis. To the best of our knowledge, the features of the current neoplasm have not been reported before: mucinous metaplasia, ER + eosinophilic cells, and a CTNNB1 mutation in a borderline-like component. The morphological, immunohistochemical and molecular features presented here further support the Müllerian, and mostly the endometrioid, origin of a subset of ovarian mesonephric-like adenocarcinomas.

Acknowledgements: The authors would like to thank $\mathrm{Mr}$ Philippe Cosmo from the Tumorothèque/Centre de Ressources Biologiques de CHU Saint-Etienne (BRIF no. BB-0033-00041), as well as Mr Emmanuel Mical for his excellent technical assistance.

Conflicts of interest and sources of funding: The authors state that there are no conflicts of interest to disclose.

Georgia Karpathiou ${ }^{1}$, Celine Chauleur ${ }^{2}$, Tiphanie Picot $^{1}$, Sofia Achour ${ }^{1}$, Thomas Corsini ${ }^{2}$, Mojgan DevouassouxShisheboran $^{3}$, Michel Peoc'h ${ }^{1}$

${ }^{1}$ Pathology Department, University Hospital of SaintEtienne, France; ${ }^{2}$ Gynecology and Obstetrics Department, University Hospital of Saint-Etienne, France; ${ }^{3}$ Pathology Department, Hospices Civils de Lyon, University Claude Bernard Lyon, France

Contact Dr Georgia Karpathiou.

E-mail: gakarpath@yahoo.gr

1. McFarland M, Quick CM, McCluggage WG. Hormone receptornegative, thyroid transcription factor 1-positive uterine and ovarian adenocarcinomas: report of a series of mesonephric-like adenocarcinomas. Histopathology 2016; 68: 1013-20.

2. Moerman P, Amant F, Vergote I. Mesonephric (Wolffian) pseudoendometrioid carcinoma of the broad ligament, arising from a papillary cystadenoma. Int J Surg Pathol 2016; 24: 635-9.

3. Ordi J, Nogales FF, Palacin A, et al. Mesonephric adenocarcinoma of the uterine corpus. Am J Surg Pathol 2001; 25: 1540-5.

4. Pors J, Cheng A, Leo JM, Kinloch MA, Gilks B, Hoang L. A comparison of GATA3, TTF1, CD10, and calretinin in identifying mesonephric and mesonephric-like carcinomas of the gynecologic tract. Am J Surg Pathol 2018; 42: 1596-606.

5. Mirkovic J, McFarland M, Garcia E, et al. Targeted genomic profiling reveals recurrent KRAS mutations in mesonephric-like adenocarcinomas of the female genital tract. Am J Surg Pathol 2018; 42: 227-33.

6. Pors J, Ho J, Prentice L, et al. c-KIT analysis and targeted molecular sequencing of mesonephric carcinomas of the female genital tract. Am J Surg Pathol 2020; 44: 495-502.

7. Mirkovic J, Sholl LM, Garcia E, et al. Targeted genomic profiling reveals recurrent KRAS mutations and gain of chromosome 1q in mesonephric carcinomas of the female genital tract. Mod Pathol 2015; 28: $1504-14$.

8. Chapel DB, Joseph NM, Krausz T, Lastra RR. An ovarian adenocarcinoma with combined low-grade serous and mesonephric morphologies suggests a Müllerian origin for some mesonephric carcinomas. Int J Gynecol Pathol 2018; 37: 448-59.

9. McCluggage WG, Vosmikova H, Laco J. Ovarian combined low-grade serous and mesonephric-like adenocarcinoma. Int J Gynecol Pathol 2020; 39: 84-92.

10. da Silva EM, Fix DJ, Sebastiao APM, et al. Mesonephric and mesonephric-like carcinomas of the female genital tract: molecular characterization including cases with mixed histology and matched metastases. Mod Pathol 2021; 34: 1570-87.

11. McCluggage WG. Endometriosis-related pathology: a discussion of selected uncommon benign, premalignant and malignant lesions. Histopathology 2020; 76: 76-92.

12. Pors J, Segura S, Chiu DS, et al. Clinicopathologic characteristics of mesonephric adenocarcinomas and mesonephric-like adenocarcinomas in the gynecologic tract. Am J Surg Pathol 2021; 45: 498-506.

DOI: https://doi.org/10.1016/j.pathol.2021.09.007

\section{Recurrent plexiform angiomyxoid myofibroblastic tumour (PAMT) of the stomach with aggressive behaviour}

To the Editor,

Plexiform angiomyxoid myofibroblastic tumour (PAMT), also known as plexiform fibromyxoma (PF), is a myofibroblastic tumour, first described by Takahashi et al. in 2007. As per the World Health Organization (WHO) 2018 classification of digestive system tumours, the term plexiform fibromyxoma has been accepted as a distinct entity among the benign mesenchymal tumours of the stomach. ${ }^{2}$ Despite this nomenclature set by WHO, many authors still prefer PAMT as a better terminology as it literally describes the morphology well. As it is a rare and recently described entity, many clinicians and pathologists are unaware of this tumour. Hence, it poses diagnostic difficulties as compared with other mesenchymal tumours of the stomach and most often gets misinterpreted as gastrointestinal stromal tumour (GIST). There has been only one such case report from India. ${ }^{3}$ Our case is the second with many undescribed features which necessitate a fresh insight into its natural history and nomenclature.

A 50-year-old female underwent upper gastrointestinal (GI) endoscopy (July 2017) 1.8 years previously for the complaint of one episode of upper GI bleeding, which demonstrated a $2 \times 2 \mathrm{~cm}$ ulcerated nodular lesion located along the lesser curvature of the body of the stomach (Fig. 1A). Endo-ultrasonography confirmed a hypoechoic lesion arising from the muscularis propria of the gastric wall, suggestive of either GIST or leiomyoma (Fig. 1B). She 


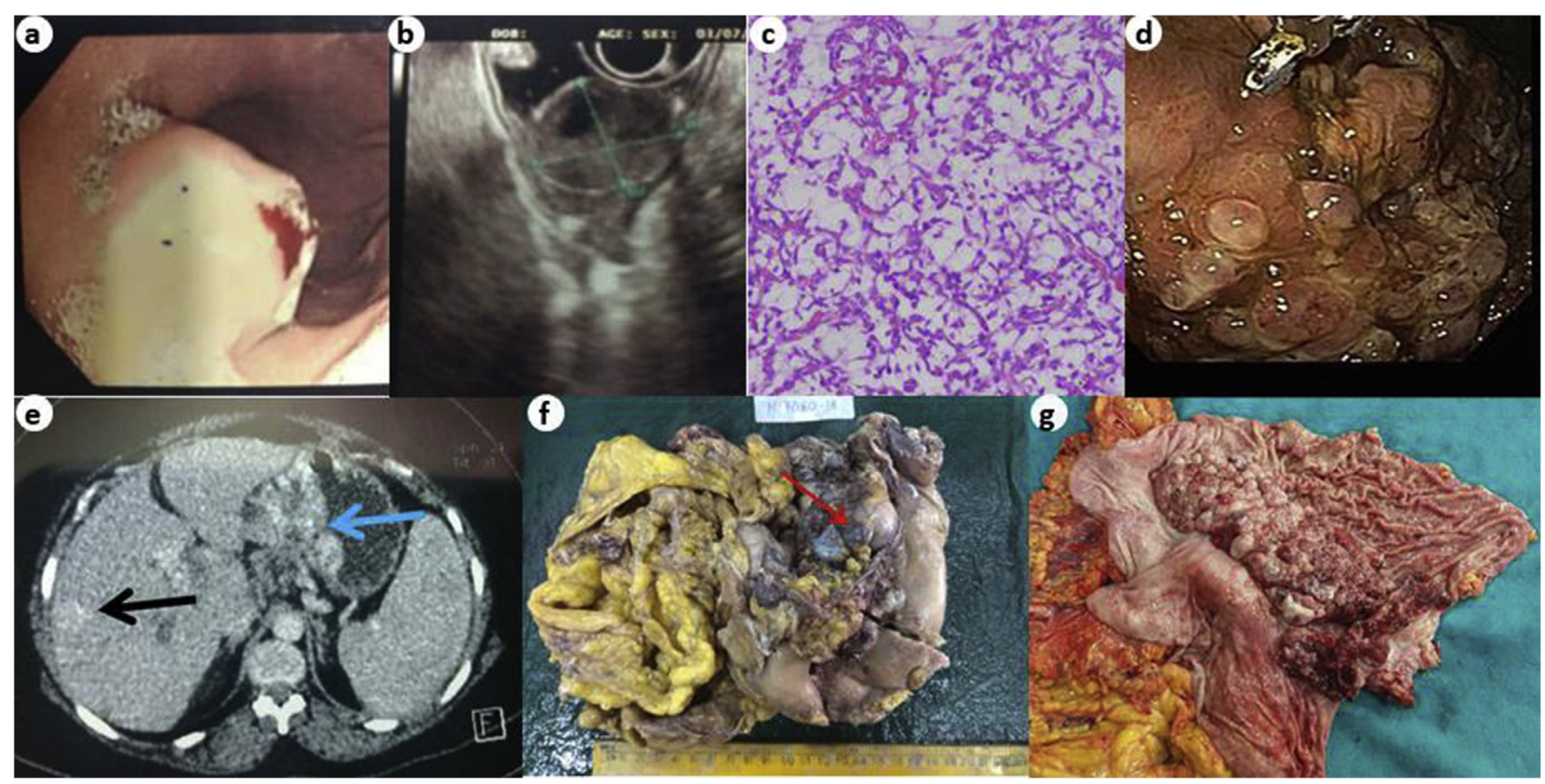

Fig. 1 (A) Upper GI endoscopy showed a $2 \times 2 \mathrm{~cm}$ ulcerated nodular lesion located along the lesser curvature of the body of the stomach. (B) Endo-ultrasonography showed a hypoechoic lesion of similar size located in the muscularis propria of the gastric wall. (C) Histopathology of endoscopic submucosal dissection (ESD) showed spindle cells with myxoid matrix and prominent thin walled blood vessels (H\&E). (D) Repeat oesophagogastroduodenoscopy showed multiple nodular ulcerated friable mucosal lesions involving the fundus and body along the lesser curvature and incisura. (E) Contrast-enhanced computed tomography (CECT) of the abdomen revealed asymmetrical irregular wall thickening with exaggerated wall thickness along the lesser curvature and antropyloric regions (blue arrow) and a well-defined arterial enhancing lesion in segments VII and VIII of the liver (black arrow). (F) Diffuse serosal multinodular lesion present throughout the lesser curvature (red arrow). (G) Total gastrectomy specimen with mucosal surface showed a greyish-white to haemorrhagic, solid, fleshy mass with multinodular/plexiform appearance.

underwent endoscopic submucosal dissection (ESD). A histopathological diagnosis of spindle cell neoplasm, possibly GIST, was offered with no definite conclusive opinion (Fig. 1C). She remained asymptomatic for one year when she was referred to our centre for recurrence of the symptoms, requiring multiple blood transfusions. Repeat oesophagogastroduodenoscopy showed multiple nodular ulcerated friable mucosal lesions involving the fundus and body along the lesser curvature and extending up to the incisura (Fig. 1D), and biopsy was performed. It showed a c-kit and DOG1 negative spindle cell neoplasm with positivity for vimentin, SMA, and MDM2. Contrast-enhanced computed tomography (CECT) of the abdomen revealed irregular wall thickening with exaggerated wall thickness along the lesser curvature and antropyloric regions and a well-defined arterial enhancing lesion in segments VII and VIII of the liver (Fig. 1E). Positron emission tomography (PET) scan (wholebody) revealed a hypermetabolic, nodular enhancing mass involving the proximal body, fundus, lesser and greater curvature of the stomach with extension to the gastrohepatic and splenic hilar region, hypermetabolic peri-gastric, periportal, portocaval, coeliac axis, and peripancreatic lymph nodes, enhancing liver space-occupying lesion (SOL), bilateral ovarian deposits, moderate ascites, and pleural effusion. Fine needle aspiration cytology (FNAC) from the liver SOL was performed, and it showed features of a low-grade sarcoma with similar nuclear morphology. Bilateral ovarian deposits were radiological findings, and there was no cytological/histological confirmation.

In view of the ongoing bleed, palliative resection was planned. Laparotomy revealed $500 \mathrm{~mL}$ of haemorrhagic ascites with multiple liver metastases, gastric mass with extraserosal extension, adherent to the head and body of the pancreas, and the coeliac axis. Enlarged lymph nodes at the porta hepatis and along the hepatic artery were noted. Total gastrectomy with Roux-en-y-oesophagojejunostomy and a feeding jejunostomy were carried out. The patient's transfusion requirement was significantly reduced after this palliative surgery. However, the patient succumbed to the disease 4 months following the surgery.

Gross examination revealed a diffuse serosal greyishbrown, multinodular lesion with focal irregularity and markedly dilated and engorged blood vessels present throughout the lesser curvature and extending into lesser omentum (Fig. 1F). The mucosal surface showed a similar lesion of size $12.5 \mathrm{~cm}$, located in the entire lesser curvature area corresponding to the serosal nodular lesions (Fig. 1G). It was a bosselated and multinodular tumour, and cut sections showed a greyish-white to greyish-brown, solid, lobulated, fleshy mass, soft to firm in consistency with nodule within nodule appearance. Adjacent gastric mucosa showed multiple tiny haemorrhagic spots. The lesser and greater omentum showed several solid nodular deposits of size ranging from $0.2-2.0 \mathrm{~cm}$. Histomorphology showed tumour arranged in a plexiform pattern (Fig. 2A) with rich arborising vascular channels and myxoid stroma (Fig. 2B). Tumour was seen invading through the muscularis propria and reaching up to the serosal fat (Fig. 2C). There were predominantly spindle cells, oval to stellate and elongated small nuclei and inconspicuous nucleoli. Scattered mitotic figures (4-5/10 high power fields), and occasional bizarre cells with pleomorphic and hyperchromatic nuclei were noted (Fig. 2D). The overlying mucosa was erosive to widely ulcerated, covered with fibrin, haemorrhage, inflammatory exudates, and underlying granulation tissue. Intra- and peri-tumoural vascular channels showed multiple 


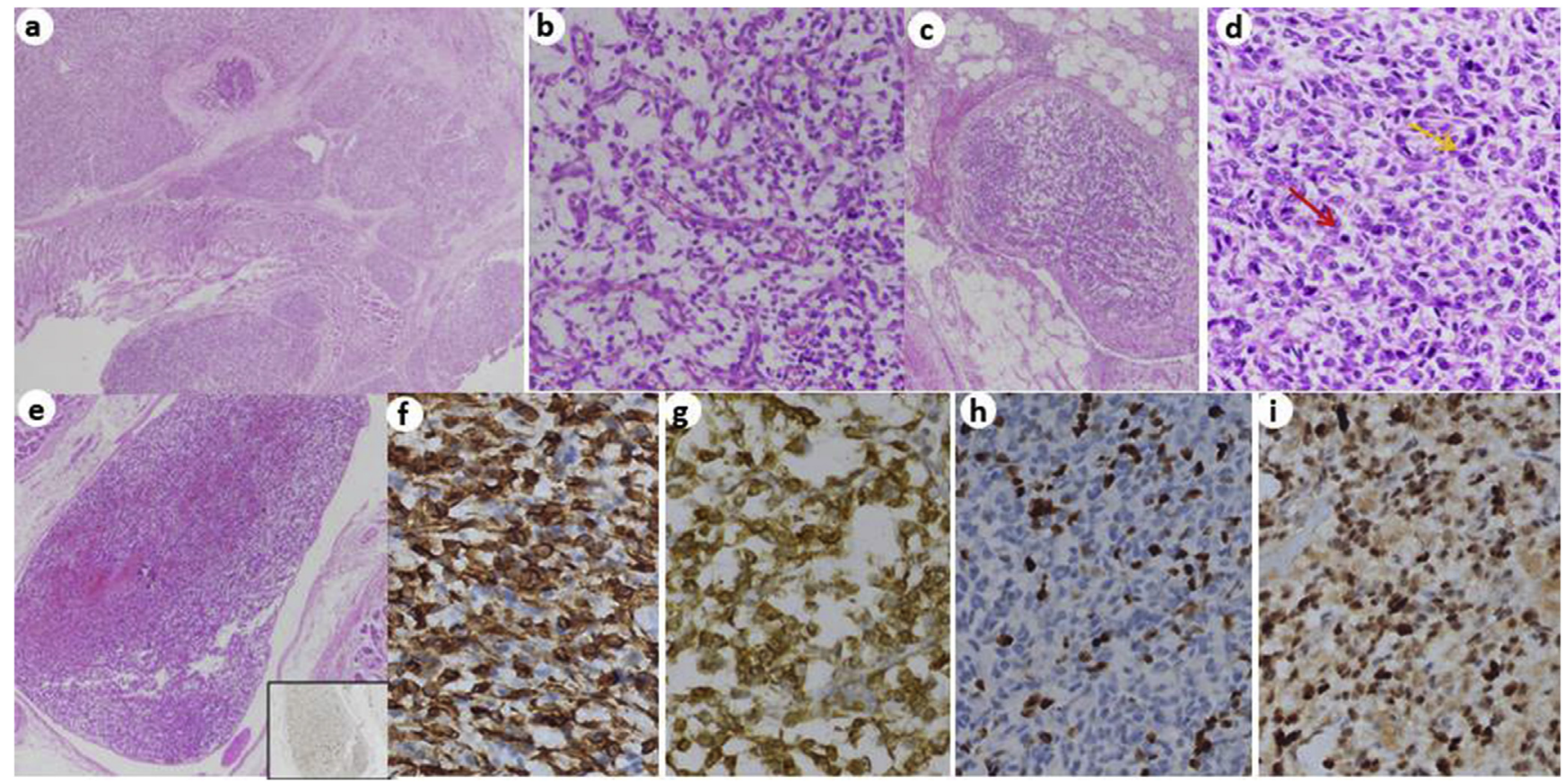

Fig. 2 (A) Gastric submucosa showing tumour arranged in plexiform pattern separated by thin fibrous septae (H\&E). (B) Spindle cells were embedded in myxoid stroma with many thin arborising capillaries in between tumour cells (H\&E). (C) Tumour was reaching up to the serosal fat (H\&E). (D) Occasional bizarre cells with pleomorphic (yellow arrow) and hyperchromatic nuclei, mitotic figures (red arrow) (H\&E). (E) Vascular invasion. Inset shows CD34 staining (IHC). (F,G,H) Tumour cells were immunopositive for SMA, MSA, MDM2 (IHC). (I) Tumour cells showed Ki-67 proliferative index 30\% (IHC).

vascular emboli (Fig. 2E). The non-caseating granulomatous reaction was seen in between tumour nodules. Greater and lesser omental tissue showed multiple nodules of tumour deposits with similar morphology. Lymph nodes along the greater and lesser curvature showed reactive changes with prominent sinusoidal dilatation and histiocytosis but no metastasis. Tumour cells were diffuse and strongly positive for SMA (Fig. 2F), muscle-specific actin (MSA; Fig. 2G), and MDM2 (focal, nuclear; Fig. 2H), with Ki-67 labelling index of $30 \%$ (Fig. 2I), and negative for pancytokeratin, desmin, c-kit, DOG1, S100, HMB45, CD34, synaptophysin, and ALK1. The morphology and immunophenotype of ESD, endoscopic biopsy (after a year of ESD), and total gastrectomy specimen were identical. A final diagnosis of plexiform angiomyxoid myofibroblastic tumour (PAMT) was given, based on the typical morphological and immunophenotypical characteristics.

Molecular analysis was performed by next-generation sequencing (NGS) with ION Torrent PGM Platform using the 50 Gene AmpliSeq v2 Panel (ThermoFisher, USA) for ckit and PDGFRA mutation analysis, which were found negative. In addition, it showed a missense mutation in exon 14 of the MET gene.

A recent study by Su et al. mentioned that only 121 cases ( $85 \mathrm{PF}$, and 36 PAMT) have been reported to date. ${ }^{4}$ Most of the cases were reported in the stomach (114 cases). In addition, a few extragastric locations like the duodenum (2 cases), jejunum (2 cases), gall bladder (1 case), and posterior mediastinum (1 case) were included in their analysis. 5,6 We analysed the following parameters in comparison with our case findings: tumour size, nuclear pleomorphism, mitotic activity and Ki-67 index, vascular invasion, metastasis, recurrence, and prognosis. Tumour size ranged from $0.8-17 \mathrm{~cm}$, and only nine cases were more than $10 \mathrm{~cm}$. Follow-up of these cases was uneventful, with a duration ranging from 3 weeks to 24 years. ${ }^{7,8}$ Our case showed a tumour size of $12.5 \mathrm{~cm}$. Most cases described in the literature are small submucosal lesions, therefore managed by distal/partial gastrectomy and mostly by endoscopic submucosal resection. In our case, it was a large mass involving almost the entire stomach and had profuse bleeding from the tumour, so it demanded total gastrectomy. Nuclear pleomorphism was not observed in most cases except one. ${ }^{9}$ We also observed this unusual finding in our case. Mitotic activity and Ki-67 index were very low. Of 121 cases, 25 mentioned Ki-67 index. Among these, 21 had a Ki-67 index of $\leq 2 \%$, two had $5 \%$, and one case had $6 \% .{ }^{10,11}$ A single case had a Ki-67 index of $30 \%$ with a mitotic rate of 3 per 10 high power fields. It did not show recurrence or metastasis after 1 year of follow-up. ${ }^{9}$ Our case also had a similar Ki-67 labelling index excluding the endothelial cells and showed recurrence and metastasis (liver and bilateral ovarian metastasis) 1 year after the ESD, and the patient died 4 months after the total gastrectomy procedure. Miettinen et al. mentioned vascular and lymphatic invasion in four of 12 cases, similar to our case, but on follow-up no recurrence was found. ${ }^{7}$ Another study by Kawara et al. also documented vascular invasion in their one case without recurrence after 4 years of follow-up. ${ }^{12}$ Most of the reported cases did not mention lymph node status except two studies which showed only reactive changes. ${ }^{8}$ We did not have metastasis in the regional lymph nodes. Distant metastasis and recurrence were not reported. On immunohistochemistry, all the reported cases showed positivity for vimentin, SMA and $\alpha$-SMA or MSA, and were negative for pancytokeratin, desmin, CD117, DOG1, S100, HMB45, CD34, synaptophysin, and ALK1. This indicates fibroblastic, myofibroblastic, or smooth muscle origin, suggesting that $\mathrm{PAMT} / \mathrm{PF}$ is a distinct entity and ruling out other close mesenchymal tumours of the stomach, which are described 
Table 1 Differential diagnosis and immunohistochemistry of PAMT

\begin{tabular}{|c|c|c|c|c|c|c|c|}
\hline \multirow[t]{2}{*}{ Differential diagnosis } & \multicolumn{5}{|c|}{ Histopathological features } & \multirow[t]{2}{*}{$\mathrm{IHC}$} & \multirow[t]{2}{*}{ Molecular profiling } \\
\hline & Cells & $\begin{array}{c}\text { Pattern of } \\
\text { arrangement }\end{array}$ & Vascularity & $\begin{array}{l}\text { Predominant } \\
\text { stromal changes }\end{array}$ & Inflammation & & \\
\hline GIST & Oval spindle cells & $\begin{array}{c}\text { Fascicles and } \\
\text { pallisades }\end{array}$ & $\begin{array}{l}\text { Hyalinised blood } \\
\text { vessels }\end{array}$ & $\begin{array}{l}\text { Hyalinisation with } \\
\text { myxoid and } \\
\text { chondroid areas }\end{array}$ & Mast cells & KIT+, DOG1+ & KIT, PDGFRA mutation \\
\hline Plexiform neurofibroma & $\begin{array}{l}\text { Thin spindled } \\
\text { cells with wavy, } \\
\text { hyperchromatic } \\
\text { nuclei }\end{array}$ & $\begin{array}{l}\text { Randomly oriented } \\
\text { and patternless }\end{array}$ & $\begin{array}{l}\text { Not a prominent } \\
\text { feature }\end{array}$ & $\begin{array}{l}\text { Thick and thin } \\
\text { collagen bands } \\
\text { with variable } \\
\text { myxoid material }\end{array}$ & Mast cells, lymphocytes & $\mathrm{S} 100+$ & - \\
\hline Myxoid leiomyoma & $\begin{array}{l}\text { Plump spindle cells } \\
\text { with blunt ended } \\
\text { nuclei }\end{array}$ & Long fascicles & $\begin{array}{l}\text { Branching blood } \\
\text { vessels }\end{array}$ & $\begin{array}{l}\text { Myxoid changes } \\
\text { focal }\end{array}$ & Mast cells & $\begin{array}{l}\text { Smooth muscle } \\
\text { actin (SMA)+, } \\
\text { caldesmon+ }\end{array}$ & - \\
\hline IFP & $\begin{array}{l}\text { Bland, uniform } \\
\text { spindled/stellate } \\
\text { cells }\end{array}$ & $\begin{array}{l}\text { Perivascular } \\
\text { concentric } \\
\text { cuffing }\end{array}$ & $\begin{array}{l}\text { Regular vascular } \\
\text { pattern }\end{array}$ & Fibromyxoid & Eosinophils & CD34+ & - \\
\hline Fibromatosis & $\begin{array}{l}\text { Spindle cells with } \\
\text { small vesicular } \\
\text { nuclei }\end{array}$ & $\begin{array}{l}\text { Short fascicles, } \\
\text { storiform and } \\
\text { haphazard }\end{array}$ & $\begin{array}{l}\text { Thin walled veins/ } \\
\text { thick walled } \\
\text { muscular } \\
\text { arteries }\end{array}$ & $\begin{array}{l}\text { Collagenous or } \\
\text { myxoid }\end{array}$ & Not prominent & B-catenin+ & - \\
\hline SFT & $\begin{array}{l}\text { Small spindloid } \\
\text { cells with dense/ } \\
\text { vesicular nuclei }\end{array}$ & $\begin{array}{l}\text { Haphazard, sheets, } \\
\text { fascicles and } \\
\text { storiform }\end{array}$ & $\begin{array}{l}\text { Ectatic staghorn } \\
\text { vessels }\end{array}$ & $\begin{array}{c}\text { Dense ropy } \\
\text { collagen }\end{array}$ & Mast cells & CD34+, STAT6+ & NAB2-STAT6 gene fusion \\
\hline IMT & $\begin{array}{l}\text { Spindled } \\
\text { myofibroblasts }\end{array}$ & Short fascicles & $\begin{array}{l}\text { Prominent } \\
\text { vascularity }\end{array}$ & $\begin{array}{l}\text { Loose myxoid } \\
\text { stroma to } \\
\text { densely } \\
\text { collagenous }\end{array}$ & Lymphocytes, plasma cells & $\begin{array}{c}\text { SMA+, ALK1 } \\
(50 \%)+\end{array}$ & - \\
\hline PAMT & $\begin{array}{l}\text { Oval to stellate } \\
\text { cells with bland } \\
\text { nuclei }\end{array}$ & $\begin{array}{l}\text { Plexiform, } \\
\text { scattered singly } \\
\text { lying cells }\end{array}$ & $\begin{array}{l}\text { Prominent } \\
\text { arborising } \\
\text { capillaries }\end{array}$ & $\begin{array}{l}\text { Large areas of } \\
\text { myxoid or } \\
\text { fibromyxoid }\end{array}$ & Not prominent & $\begin{array}{c}\text { Vimentin+, } \\
\text { SMA+, } \\
\alpha-\text { SMA+ }\end{array}$ & - \\
\hline
\end{tabular}

GIST, gastrointestinal stromal tumour; IFP, inflammatory fibroid polyp; IMT, inflammatory myofibroblastic tumour; IHC, immunohistochemistry; PAMT, plexiform angiomyxoid myofibroblastic tumour; SFT, solitary fibrous tumour. 
in Table 1. In addition, focal nuclear positivity for MDM2 here may have potential therapeutic implications, which was not mentioned in the previous studies. Mutational analysis for c-kit and PDGFRA was wild type in our case, which is similar to the previously reported cases. On the other hand, our case showed a positive missense mutation in exon 14 of the MET gene. The MET activation was found in around $15 \%$ of GIST, in a situation such as untreated GIST, during the response to imatinib and upon imatinib resistance. Neither a diagnosis of GIST nor any therapy in this line was offered.

The unusual morphology and aggressive clinical behaviour with fatal outcome observed in our case needs molecular and genetic analysis in a larger group of cases to characterise it further. Moreover, none of the literature has mentioned the recurrence of PAMT. This is the first case to our knowledge showing recurrence and distant metastasis with fatal outcome. Although most of the cases described in the literature were benign c-kit negative mesenchymal tumours, recurrence of the tumour after resection with distant metastasis in the present case certainly raises the question of its classification under the benign category.

Acknowledgement: The authors thank Dr Mayur Parihar, Consultant Pathologist, Department of Cytogenetics, Tata Medical Centre, Kolkata, India, for reporting the fluorescent in situ hybridisation (FISH) of MDM2.

Conflicts of interest and sources of funding: The authors state that there are no conflicts of interest to disclose.

\section{Pavithra Ayyanar ${ }^{1}$, Hemanta Kumar Nayak², Subash Chandra Samal' ${ }^{2}$, Madhabananda Kar $^{3}$, Pritinanda Mishra ${ }^{1}$, Susama Patra ${ }^{1}$}

${ }^{1}$ Department of Pathology and Lab Medicine, All India Institute of Medical Sciences, Bhubaneswar, Odisha, India; ${ }^{2}$ Department of Medical Gastroenterology, All India Institute of Medical Sciences, Bhubaneswar, Odisha, India; ${ }^{3}$ Department of Surgical Oncology, All India Institute of Medical Sciences, Bhubaneswar, Odisha, India

Contact Dr Susama Patra, MD.

E-mail: wususama@gmail.com

1. Takahashi Y, Shimizu S, Ishida T, et al. Plexiform angiomyxoid myofibroblastic tumor of the stomach. Am J Surg Pathol 2007; 31: 724-8.

2. Miettinen M, Fletcher CDM, Kindblom LG, et al. Mesenchymal tumors of stomach. In: Bosman FT, Carneiro F, Hruban RH, Theise ND, editors. WHO Classification of Tumors of the Digestive System. 4th ed. Lyon: IARC, 2018; 74-9.

3. Dixit JD, Sharief SA, Goyal MK, et al. Plexiform angiomyxoid myofibroblastic tumor (PAMT) of stomach with synchronous bilateral cystic ovarian neoplasms, a rare case presentation. Indian J Surg Onco 2016; 7: 82-5.

4. Su HA, Yen HH, Chen CJ. An update on clinocopathological and molecular features of plexiform fibromyxoma. Can J Gastroenterol Hepatol 2019; 2019: 3960920.

5. Fassan M, Salmaso R, Saraggi D, et al. Plexiform fibromyxoma of the gallbladder. Pathologica 2015; 107: 181-4.

6. Zhang WG, Xu LB, Xiang YN, et al. Plexiform fibromyxoma of the small bowel: a case report. World J Clin Cases 2018; 6: 106772 .

7. Miettinen M, Makhlouf HR, Sobin LH, et al. Plexiform fibromyxoma: a distinctive benign gastric antral neoplasm not to be confused with a myxoid GIST. Am J Surg Pathol 2009; 33: 1624-32.
8. Yang MX, Zhao ZH, Yang JF, et al. Imaging findings of gastric plexiform fibromyxoma with a cystic change: a case report and review of literature. Medicine (Baltimore) 2017; 96: e8967.

9. Lai J, Kresak JL, Caoet D. Gastric plexiform fibromyxoma: a great mimic of gastrointestinal stromal tumor (GIST) and diagnostic pitfalls. J Surg Res 2019; 239: 76-82.

10. Ni Z, Xie XM, Xu H. Gastric plexiform fibromyxoma: a case report and literature review. World Chin J Digestol 2015; 23: 5085-8.

11. Kang Y, Jung W, Do IG, et al. Plexiform angiomyxoid myofibroblastic tumor of the stomach: report of two cases and review of the literature. Korean J Pathol 2012; 46: 292-6.

12. Kawara F, Tanaka S, Yamasaki T, et al. Gastric plexiform fibromyxoma resected by endoscopic submucosal dissection after observation of chronological changes: a case report. World J Gastrointest Oncol 2017; 9: $263-7$.

DOI: https://doi.org/10.1016/j.pathol.2021.09.010

\section{Thrombospondin type-1 domain- containing 7A-related membranous nephropathy associated with glomerular AL amyloidosis}

To the Editor,

Immunoglobulin light chain amyloidosis (AL amyloidosis) is a systemic severe disease that predominantly affects the kidneys and the heart, with cardiac amyloidosis as a major determinant of outcome. Renal involvement typically manifests with nephrotic syndrome and/or deterioration of kidney function, with amyloid deposits mainly observed within the glomeruli and vessel walls. It usually occurs in patients with plasma cell clones but may also result, in rare cases, from Waldenström macroglobulinaemia (WM) and other B-cell lymphoproliferative disorders. Autologous stem cell transplantation (SCT) associated with high dose chemotherapy has improved haematological response and survival in selected patients with AL amyloidosis. Organ response is often delayed after a favourable haematological response, with organ recovery strongly associated with the depth of the haematological response achieved. ${ }^{1,2}$ Even in cases of successful haematological response, patients with AL amyloidosis can experience a progressive decline of renal function and a worsening of proteinuria. ${ }^{1,3}$ Iterative kidney biopsies may show the persistence of or increases in renal amyloid deposits ${ }^{3-5}$ without identifying recent amyloid deposits, and thus may not be helpful in the therapeutic management. We report a patient who presented with nephrotic syndrome 5 years after autologous SCT for systemic AL amyloidosis related to WM. Strikingly, renal biopsy demonstrated Thrombospondin type-1 domain-containing 7A (THSD7A)related membranous nephropathy $(\mathrm{MN})$ associated with glomerular AL amyloidosis.

In 2011, a 56-year-old man was diagnosed with biclonal WM, with monoclonal IgM lambda (32 g/L) and IgG lambda $(12 \mathrm{~g} / \mathrm{L})$ spikes associated with a decrease in free light chain ratio $[\mathrm{kappa} / \mathrm{lambda}(\kappa / \lambda)$ ratio $=0.18$; normal range $0.26-$ 1.65] on immunonephelometric assays.

At the time of WM diagnosis, whole-body magnetic resonance imaging revealed diffuse infiltration of the retroperitoneal and mesenteric adipose tissue due to biopsyproven AL-lambda amyloidosis. Amyloid deposits were also observed on bone marrow and bladder biopsies. 